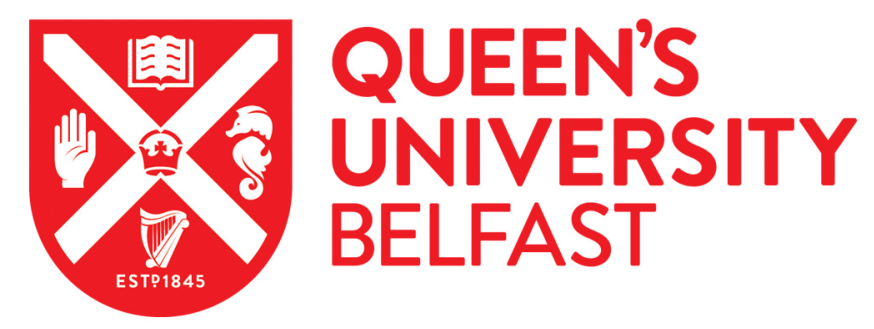

\title{
Asymmetric hydrogen flame in a heated micro-channel: role of Darrieus-Landau and thermal-diffusive instabilities
}

Alipour, A., Mazaheri, K., Shamounipour, A., \& Mahmoudi, Y. (2016). Asymmetric hydrogen flame in a heated micro-channel: role of Darrieus-Landau and thermal-diffusive instabilities. International Journal of Hydrogen Energy, 41(44), 20407-20417. https://doi.org/10.1016/j.ijhydene.2016.09.099

Published in:

International Journal of Hydrogen Energy

Document Version:

Peer reviewed version

Queen's University Belfast - Research Portal:

Link to publication record in Queen's University Belfast Research Portal

Publisher rights

(c) 2016 Elsevier Ltd. This manuscript version is made available under the CC-BY-NC-ND 4.0 license http://creativecommons.org/licenses/by$\mathrm{nc}-\mathrm{nd} / 4.0 /$ which permits distribution and reproduction for non-commercial purposes, provided the author and source are cited.

\section{General rights}

Copyright for the publications made accessible via the Queen's University Belfast Research Portal is retained by the author(s) and / or other copyright owners and it is a condition of accessing these publications that users recognise and abide by the legal requirements associated with these rights.

Take down policy

The Research Portal is Queen's institutional repository that provides access to Queen's research output. Every effort has been made to ensure that content in the Research Portal does not infringe any person's rights, or applicable UK laws. If you discover content in the Research Portal that you believe breaches copyright or violates any law, please contact openaccess@qub.ac.uk. 


\title{
Asymmetric hydrogen flame in a heated micro-channel: role 1 of Darrieus-Landau and thermal-diffusive instabilities $\quad 2$
}

\author{
Alireza Alipoor ${ }^{1}$, Kiumars Mazaheri $^{* 1}$, Ali Shamounipour ${ }^{1}$, Yasser Mahmoudi $^{2}$ \\ 1 Faculty of Mechanical Engineering, Tarbiat Modares University, Tehran, 14115-111, Iran \\ 2 Department of Engineering, University of Cambridge, Trumpington Street, Cambridge CB2 1PZ, United 6 \\ Kingdom 7 \\ * Correspondence to 9 \\ Email: kiumars@modares.ac.ir; Tel.: +98-2182883352; Fax: +98-21-82883962 10
}

$\begin{array}{ll}\text { Abstract } & 12\end{array}$

Present work examines numerically the asymmetric behavior of hydrogen/air flame in a micro- 13 channel subjected to a non-uniform wall temperature distribution. A high resolution (with cell 14 size of $25 \mu \mathrm{m} \times 25 \mu \mathrm{m}$ ) of two-dimensional transient Navier-Stokes simulation is conducted in 15 the low-Mach number formulation using detailed chemistry evolving 9 chemical species and $21 \quad 16$ elementary reactions. Firstly, effects of hydrodynamic and diffusive-thermal instabilities are 17 studied by performing the computations for different Lewis numbers. Then, the effects of 18 preferential diffusion of heat and mass transfer on the asymmetric behavior of the hydrogen 19 flame are analyzed for different inlet velocities and equivalence ratios. Results show that for the 20 flames in micro-channels, interactions between thermal diffusion and molecular diffusion play 21 major role in evolution of a symmetric flame into an asymmetric one. Furthermore, the role of 22 Darrieus-Landau instability found to be minor. It is also found that in symmetric flames, the 23 Lewis number decreases behind the flame front. This is related to the curvature of flame which 24 leads to the inclination of thermal and mass fluxes. The mass diffusion vectors point toward the 25 walls and the thermal diffusion vectors point toward the centerline. Asymmetric flame is 26 observed when the length of flame front is about 1.1 to 1.15 times of the channel width. 27

Keywords: Steady asymmetric flame, Diffusive-thermal instability, Darrieus-Landau instability, $\quad 29$ Lewis number 30

1. Introduction 32

For the need of high energy density the study of microscale combustion has attracted significant 33 interests over the last decade leading to the miniaturization of sustainable industrial 34 
combustion process. To apply the concept of micro-combustion in process engineering, the

problems arise by reducing the combustion volume need to be addressed carefully. Combustion

in such small combustors is different from their macro scale counterparts. This is mainly

because in micro-scales, strong interactions between the flame and combustor walls result in

different characteristics and behaviors of the confined flame.

One of the main topics in combustion in micro-scales is to find methods for extending

flammability limits. Various works have been done in this topic in the past decades. Wan et al. investigated the effect of different bluff bodies [1] and wall cavities [2] in a planar microchannel on flammability limits of $\mathrm{H}_{2}$-air combustion. They observed that blow-off limit is greatly extended as compared with that of the micro-combustor without using them. Yan et al. [3]showed the beneficial effects of hydrogen addition on catalytic methane- air combustion on flame stability.

Different flame regimes have been reported in previous experimental and numerical studies of flames in micro-scale. These are weak flames, repetitive extinction-ignition dynamics, steady symmetry flame and steady asymmetric flame. This paper focuses on the steady asymmetric 49 flame.

One of the most common regimes appears in micro-scale combustion is the steady asymmetric regime which happens in the upper flammability limits. Stable flame may lose its 52 symmetry (respect to the centerline of the micro-channel). The resulting shapes often called upper or lower asymmetric flames [4].

Dogwiler et al. [5] experimentally studied the combustion of lean premixed methane/air $(\varphi=0.33)$ in a planar channel with $7 \mathrm{~mm}$ width . Both symmetric and asymmetric flames were observed in this work. They concluded that the sensitivity of the flame to external perturbations that existed in their experiment resulted in a random upper and lower asymmetric flame 58 behaviors. Steady asymmetric flames were also observed by Kurdyumov et al. ([6], [7]) in their 59 study of methane/air and propane/air flame propagation. They observed asymmetric stable $\quad 60$ flames in the upper flammability limits. This was in agreement with findings of Dogwiler et al. $\quad 61$ [1]. The emphasize in their work was to investigate the flashback limits of the flame in micro- 62 scale ([6], [7]), and the physics underlying the asymmetric behavior of the flame was not 63 discussed in their study.

It is now well demonstrated that hydrodynamic, body-force and diffusive-thermal effects are three types of phenomena that may cause the intrinsic instabilities of premixed subsonic flames in micro or macro scales [8]. The hydrodynamic effect is due to thermal expansion across the flame [9]. The body-force effect is due to the difference in the densities of burnt and unburnt mixtures across the flame [9]. This difference may give rise to buoyant instabilities in flames 
preferential diffusion of mass and heat of reaction [9]. Based on the value of Lewis number, two

types of diffusive-thermal instability can be distinguished, (i) cellular instability for Lewis 72 numbers smaller than a critical value (typically less than one), and (ii) pulsating instability for 73 Lewis numbers above this critical value.

To study the diffusive-thermal instability effects, there are two reported methods. The 75 first one is to assume that the density of the flow is constant. To this end, the governing 76 equations are solved utilizing thermal-diffusive formulations (e.g. [10] and [11]). The other 77 method is to use non-unity Lewis number (e.g., [12]). Altantzis et al. [12] investigated the effect 78 of hydrodynamic and diffusive-thermal instabilities in lean premixed hydrogen/air planar 79 flames using DNS and utilizing a one-step global reaction model. They considered the effective 80 Lewis number equals to 0.404 , where the diffusive-thermal instability exists.

Petchenko and Bychkov [13], using linear stability analysis, studied the stability of a flame 82 in a micro cylindrical tube with adiabatic walls and asymmetric perturbations. They showed 83 that for tubes with diameters higher than a critical value, small perturbations grow 84 exponentially that make the flame asymmetric. They stated that the critical value is proportional 85 to the cutoff wavelength $\left(\lambda_{c}\right)$ of the Darrieus-Landau (DL) instability. Tsai [14] investigated 86 numerically the steady propagation of a premixed laminar methane/air flame in tubes of 87 different diameters in micro-scale. The simulations were carried out in two- and three88 dimensions with isothermal walls, a one-step global reaction model and using unity Lewis 89 number assumption. He [14] found that asymmetric flames occurs only in ducts with diameters 90 higher than the critical value, $120 \times \mathrm{l}_{\mathrm{f}}\left(\mathrm{l}_{\mathrm{f}}\right.$ is the flame thickness) [14]. This was in agreement with 91 linear stability analysis of Petchenko and Bychkov [13]. They ([13], [14]) related this behavior 92 to the secondary DL instability as mentioned by Liberman et al [15].

Liberman et al. [15] studied the propagation of a laminar flame in wide tubes (with 94 diameter higher than 3.4 times of the cut-off wavelength) using direct numerical simulation. To 95 exclude the effects of thermal-diffusive instability, they assumed the Lewis number is unity. 96 Furthermore, they assumed slip and adiabatic conditions on the tube walls to omit the small 97 disturbances on the flame edge caused by the wall friction, viscosity and heat losses. Their 98 results showed that perturbations with a wavelength shorter than $\lambda_{c}$ were stabilized by the 99 thermal effects. While perturbations with higher wave lengths grow exponentially and cause 100 instabilities. They concluded that for occurrence of DL instability, the tube width should be higher than half of the cut-off wavelength. Bychkov and Liberman [16] stated that for a realistic flame the cut-off wavelength is about $20 \mathrm{l}_{\mathrm{f}}-40 \mathrm{l}_{\mathrm{f}}$. They also reported that the respective wavelength of the fastest perturbations is twice larger than the cut-off wavelength, which is about two orders of magnitude greater than the flame thickness. 
Pizza et al. [4] investigated the dynamics of lean $(\varphi=0.5)$ premixed hydrogen/air flames 106 in micro and meso scale channels using two-dimensional direct numerical simulation. They 107 observed a stable V-shaped symmetric flame at a fixed channel height and inlet velocity. 108 However, after a transition stage by increasing the inlet velocity, the flame became stable in an 109 asymmetric shape. Using Bychkov and Liberman [16] analysis, they mentioned that the 110 diffusive-thermal instability was the reason of this behavior. Besides, they stated that since the width of the chambers in micro-scales is typically lower than half of the cut-off wavelength, the DL instability cannot happen. Hence, the thermal-diffusive instability is expected to be the main reason of asymmetric behavior of flames in micro-scales. In this condition, flame stretching has a stabilizing effect on the flame front while the heat losses counteract this effect.

The present review of literature shows that the study of asymmetric flame behavior in micro-scales is still being challenged by the sophisticated nature of the effects of two instabilities (i.e. Darrieus-Landau and thermal-diffusive), in transition of symmetric flame to asymmetric one. Experimental discrimination between these two instabilities in appearance of asymmetric flame behavior in micro-scale is really challenging. Due to these complications, it is very useful to perform a high fidelity numerical investigation to differentiate the role of different factors in flame instability and asymmetric behavior under varying parameters (e.g. Lewis number). Through a series of numerical investigations, the present work aims at studying the behavior of the asymmetric flame in micro-scale combustion to shade light on the reasons of the occurrence of this phenomenon.

The problem includes combustion of hydrogen/air mixture in a micro-channel with predefined wall temperature. A 2D low-Mach laminar Navier-Stokes solver with detailed 127 kinetics and multi species diffusions is developed. Another aim is to study the instabilities exist in this type of combustion. To investigate the effects of these instabilities, first, the conditions. To quantitatively parameterize the asymmetric behavior of flames in micro-scales, a criterion is drawn using the curvature of flame.

\section{Governing equations and Numerical procedure}

In the present work, we assumed that the characteristic length of the combustion chamber is sufficiently larger than the molecular mean free path of the reacting flow gases. 
assumed that the effect of radiation on the combustor wall is negligible. The gas radiation is

neglected and the wall of the combustor is assumed to be inert (no absorption or desorption of

species). Viscous heating is neglected due to the dominant conduction heat transport. Buoyancy

effect is neglected due to the high inlet velocity implying that convection is the primary mode of

heat transfer. It is reported by Kuo and Ronney [19] that for Reynolds number beyond 500 the

turbulence modeling is necessary in order to have a good quantitative agreement for numerical

modeling of reacting flows in micro combustors. In the present work the Reynolds number is in

interval of 100 to 400 and hence the flow is considered to be laminar. The present simulations are limited to two-dimensional modeling, thus typical three-dimensional effects are neglected.

In a two-dimensional DNS framework for micro planner channels, Pizza et al. ([4], [20], [21])

The phenomenon of asymmetry would not happen in the case of cylindrical tubes where experimental results. Instead we aim at analyzing the role of Darrieus-Landau and thermaldiffusive instabilities on the behavior of the asymmetric flame in micro-scale combustion. Thus, investigating a 2D planar channel modeling is appropriate.

According to the above assumptions, governing equations including the continuity,

Continuity:

$$
\frac{\partial \rho}{\partial \mathrm{t}}+\nabla \cdot(\rho u)=0
$$

Momentum:

$$
\rho\left(\frac{\partial u}{\partial \mathrm{t}}+u \cdot \nabla u\right)=-\nabla p_{d}+\nabla \cdot(\mu S)
$$




$$
\rho c_{p}\left(\frac{\partial T}{\partial \mathrm{t}}+u \cdot \nabla T\right)=\nabla \cdot(\lambda \nabla T)-\sum_{\mathrm{i}=1}^{\mathrm{N}_{\mathrm{g}}} h_{i} \dot{\omega}_{l}-\rho\left(\sum_{\mathrm{i}=1}^{\mathrm{N}_{\mathrm{g}}} c_{p, i} Y_{i} V_{i}\right) \cdot \nabla T
$$

where $\rho, u$, and $\mu$ are density, velocity and dynamic viscosity, respectively. $p_{d}$ is the 171 hydrodynamic pressure. The stress tensor (S) in equation (2) is defined as " $\nabla u+(\nabla u)^{\mathrm{T}}-$ 172 $\frac{2}{3}(\nabla . u) I$ ", where "I" is the identity matrix. In equation (3), $\lambda, c_{p, i}$ and $h_{i}$ are the mixture thermal 173 conductivity, heat capacity, and enthalpy of the $i^{\text {th }}$ specie, respectively.

The ideal gas equation of state is written as:

$$
p_{t}=\rho \frac{R_{u}}{\bar{W}} T
$$

where, $\bar{W}$ is the mean molecular weight of the mixture and $R_{u}$ is the universal gas constant. 176 Here, $p_{t}$ is the thermodynamic pressure which is assumed to be constant in low-Mach number 177 assumption.

The species conservation equation is written as:

$$
\rho\left(\frac{\partial Y_{i}}{\partial \mathrm{t}}+u \cdot \nabla Y_{i}\right)=-\nabla \cdot\left(\rho Y_{i} V_{i}\right)+\dot{\omega}_{l}
$$

where, $\dot{\omega}_{l}$ is the consumption/production rate of $i^{\text {th }}$ specie which is calculated by equations (8- 180 10). Here, $Y_{i}$ and $V_{i}$ are the mass fraction and diffusion velocity of $i^{\text {th }}$ specie. $V_{i}$ is calculated using 181 equation (6):

$$
V_{i}=V_{i}^{*}+V_{c}
$$

where, $V_{i}^{*}$ is evaluated by the kinetic theory of gases by considering only mixture averaged 183 diffusion. $V_{c}$ is defined as the correction velocity to numerically guarantee total mass 184 conservation:

$$
\mathrm{V}_{c}=-\sum_{\mathrm{i}=1}^{\mathrm{N}_{\mathrm{g}}} Y_{i} \mathrm{~V}_{i}^{*}, \mathrm{~V}_{i}^{*}=-\left(\frac{\mathrm{D}_{i m}}{\mathrm{X}_{i}}\right) \nabla \mathrm{X}_{i}
$$

where, $\mathrm{D}_{\mathrm{im}}$ is the average diffusivity of the $i^{\text {th }}$ specie and $X_{i}$ is the mole fraction of $i^{\text {th }}$ specie. Fick 186 law is used for calculation of $D_{i m}$ and $D_{i j}$ is evaluated using Chapman-Enskog model [23].

One of the conventional geometries to study the micro-scale combustion is the heated 188 micro-channel which has been regarded as cylindrical tube ([24]-[26]) or planner channel 189 ([27], [5]). The schematic of the heated micro-channel is shown in Fig. 1. A part of the channel 
(i.e. test section in Fig. 1) is heated by an external source. A temperature distribution, used in

The no-slip boundary conditions for velocity and zero-flux for all species are applied at the walls of chamber. For all variables at the outlet, Neumann boundary conditions are imposed (i.e. $\frac{\mathrm{d} Y_{i}}{\mathrm{~d} x}=0 ، \frac{\mathrm{d} T}{\mathrm{~d} x}=0$ and $\frac{\mathrm{d} u}{\mathrm{~d} x}=0$ ).

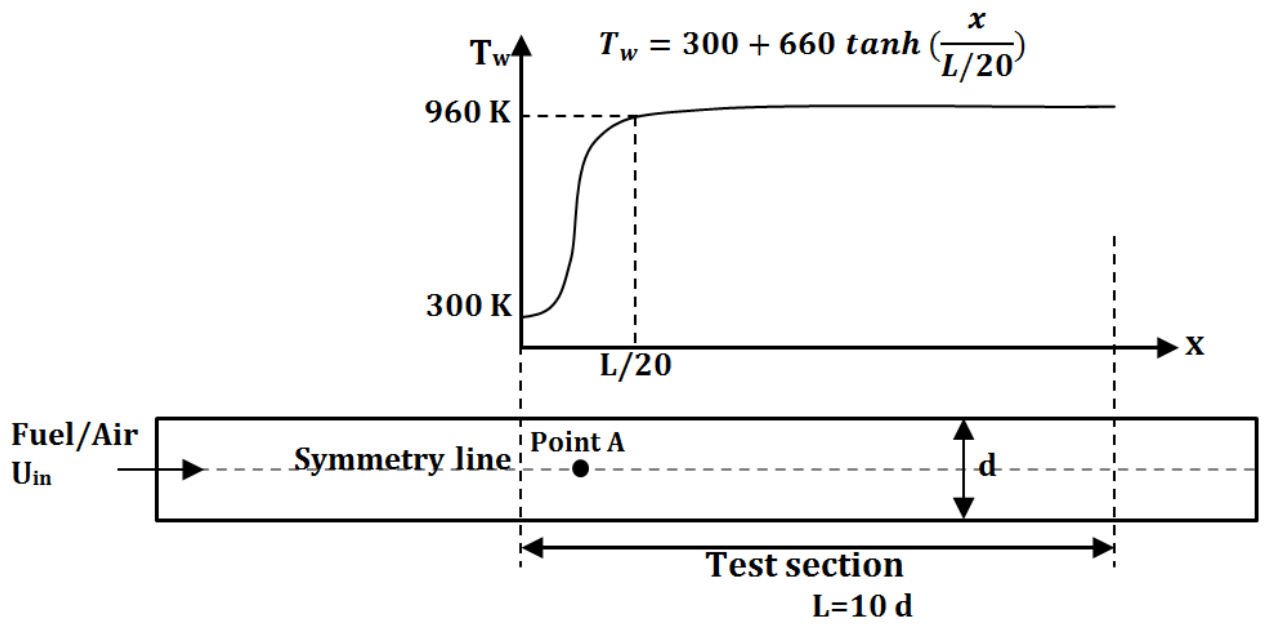

Fig. 1: The schematic of the heated micro-channel with temperature distribution on the external walls.

The detailed reaction mechanism of Yetter et al. [28] with 9 chemical species and 21 reversible elementary reactions is utilized. A reactive solver is developed in OpenFOAM to solve the governing equations (1-7). A new solver named "RITLFOAM" is developed according to the problem requirements which consider a Low-Mach number formulation of Navier-Stokes equations and multi species transport model. The accuracy of the numerical solver is 200 established in[29]. For further validation of the developed solver we study a one-dimensional laminar flame and compare the results with those predicted using Chemkin code. A two202 dimensional geometry with periodic boundary conditions along the horizontal boundaries is studied. The flame structure including temperature, velocity and species mass fraction obtained using the developed solver is in good agreement (see Figs. 2a and $2 \mathrm{~b}$ ) with the results predicted 205 using Chemkin code. 


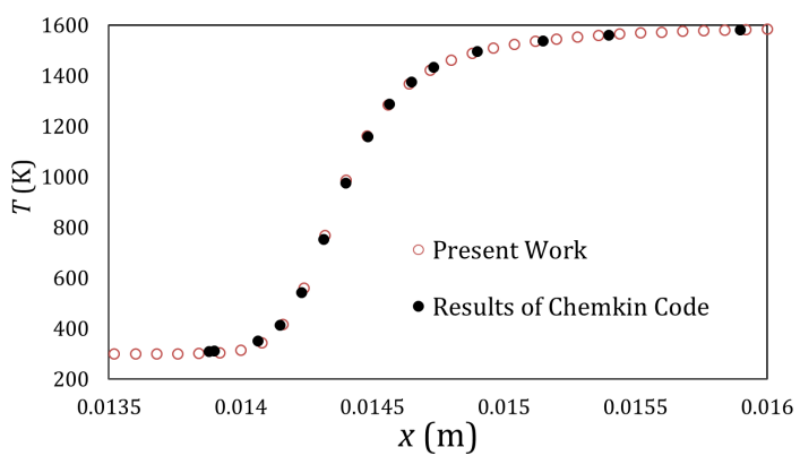

(a)

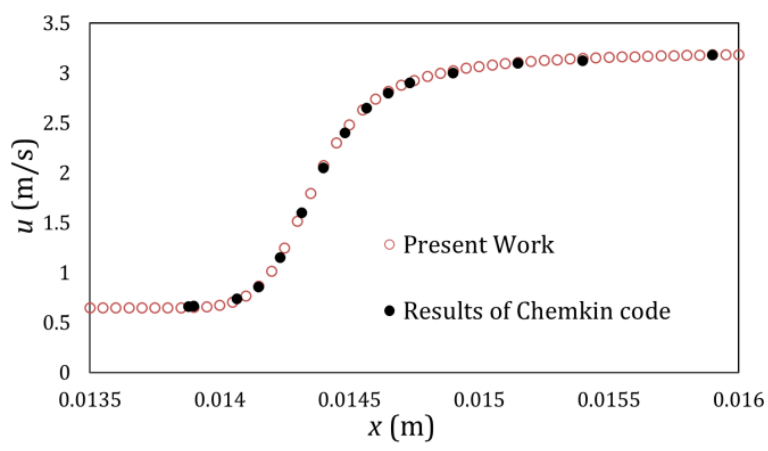

(b)

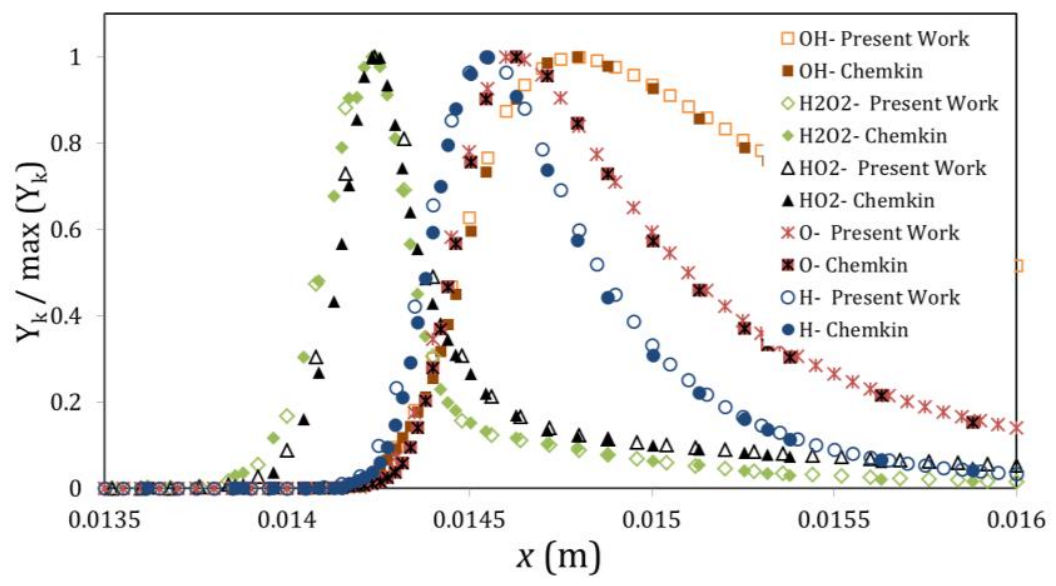

(c)

Fig. 2: Structure of one-dimensional hydrogen-air premixed flame: comparison of (a) temperature, (b) velocity and (c) normalized mass fraction of species calculated in the present work against those predicted by Chemkin code.

To ensure that the results provided are independent of the grid resolution, different size meshes were employed to test the numerical model. Fig. 3 shows that increasing the grid points results in the convergence of the computed temperature along the channel axis. The results obtained for $50 \mu \mathrm{m} \times 50 \mu \mathrm{m}$ and $25 \mu \mathrm{m} \times 25 \mu \mathrm{m}$ are very much similar. Hence, the grid size of 25 $\mu \mathrm{m} \times 25 \mu \mathrm{m}$ was used for all the computations in the present work. The time step is automatically calculated in order to satisfy specific tolerances in ODE solver of reaction rate term. So, time step is obtained between $10^{-7}$ and $10^{-8} \mathrm{~S}$. 


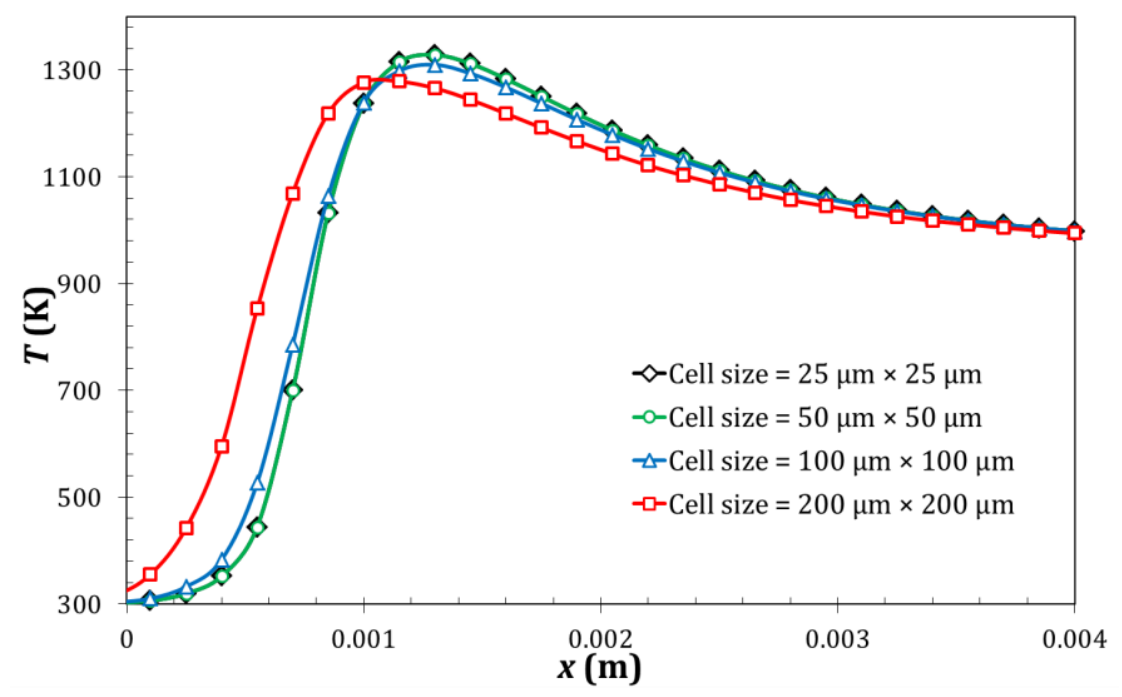

Fig. 3: Temperature variation on symmetry line of the channel for different cell size for channel with width $=1 \mathrm{~mm}$, equivalence ratio $=0.5$ and inlet velocity $=50 \mathrm{~cm} / \mathrm{s}$.

Further details on the solver developed, validation of the results can be found in Ref. [29]. 214

3. Results and discussion

In this section we investigate (i) the flame evolution from 'symmetric' to 'asymmetric' by analyzing the contours of $\mathrm{OH}$ radicals, (ii) we examine the role of two types of instabilities (i.e. Darrieus-Landau and thermal-diffusive) on flame structures by utilizing different Lewis numbers, (iii) we further study the effects of inlet velocity and equivalence ratio on the interaction of thermal and mass diffusions, and (iv) in order to find a criterion for the flame asymmetric behavior the accurate value of Lewis number for various inlet conditions is evaluated by considering multi species transport model and Fick's law.

In the present work, similar to the results given by Pizza et al. $[4,20]$ upper and lower 
The process of evolving a symmetric flame into an asymmetric shape in a heated micro-
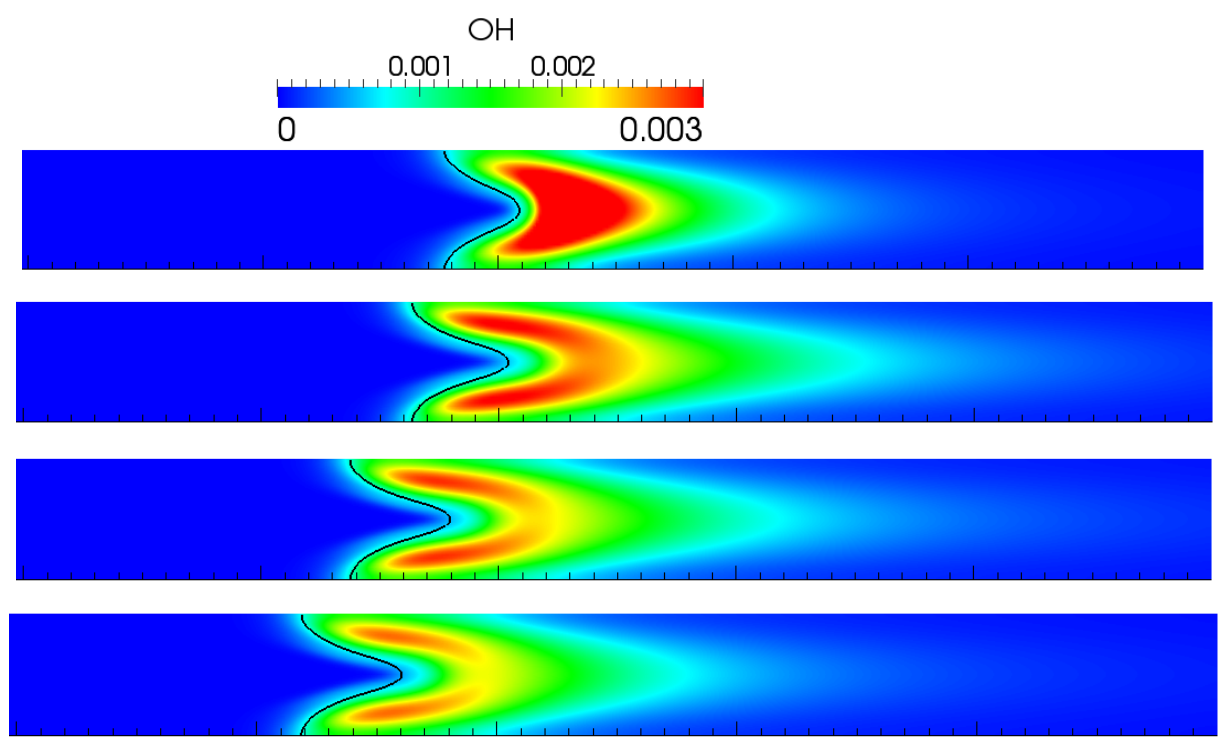

\section{(c)}
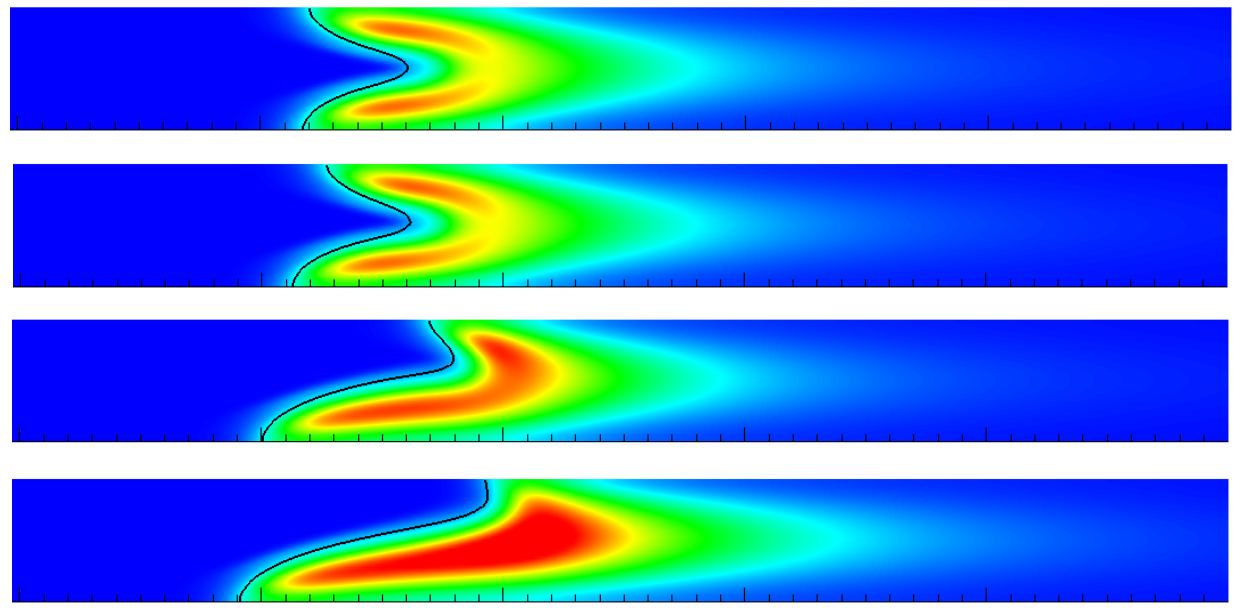

(g)

$t=0.0065 \mathrm{~s}$

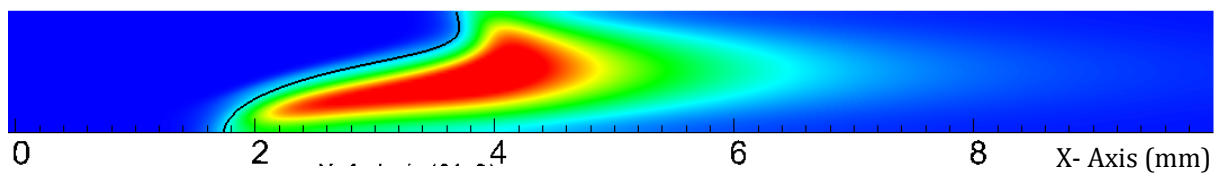

(h)

$\mathrm{t}=0.007 \mathrm{~s}$

$\mathrm{t}=0.009 \mathrm{~s}$

Fig. 4: Time evolution of contour of $\mathrm{OH}$ mass fraction of a hydrogen flame in a micro-channel with width $=1 \mathrm{~mm}$, inlet velocity $=300 \mathrm{~cm} / \mathrm{s}$ and $\varphi=0.5$.

After an ignition process, a symmetric flame forms which is seen in Fig. 4a. At this time the maximum value of $\mathrm{OH}$ mass fraction is 0.0045 occurs at the channel centerline. At the interval between $0.001 \mathrm{~s}$ and $0.0045 \mathrm{~s}$, Figs. $4 \mathrm{~b}$ to $4 \mathrm{~d}$ show that $\mathrm{OH}$ radicals move toward the heated walls and the flame front moves upstream of the channel. However, in the new flame position, the reaction rate decreases. This reduction is obvious in the maximum of $\mathrm{OH}$ mass fraction after 0.001s (Figs. 4b-4d). Inspection of Figs. 4d and 4e shows that in the interval 
between $0.0045 \mathrm{~s}$ and $0.0055 \mathrm{~s}$, the flame is stationary. At this instant, the flame is highly

unstable and a perturbation can give rise to instability of the flame. The evolution into the

second stable mode, which is asymmetric in shape, is clearly seen in Figs. $4 \mathrm{f}$ to $4 \mathrm{i}$. These figures

further show that the $\mathrm{OH}$ mass fraction increases in the evolution of a symmetric flame to an

asymmetric shape. This is due to an increase in the flame surface area, which increases the reaction rate and consequently an increase in the mass fraction of $\mathrm{OH}$ radicals.

In order to better understand the process of evolution a symmetric flame into the asymmetric shape Fig. 5 is shown here. In this figure black lines represent the flame front where the fuel mass fraction is 0.0077 (i.e. half of the incoming fuel mass fraction [4]). Figure 5(a) shows that before transition to the asymmetric shape, the velocity vector normal to the flame front $\left(U_{n}\right)$ is equal to the local burning velocity $\left(S_{L}\right)$ in both A-B and B-C branches [23]. If one of the branches moves from $C$ to $C^{\prime}$ due to physical or numerical perturbations (Fig. 5b), the magnitude of the velocity vector normal to the flame surface increases and becomes greater than the local burning velocity (due to variation in the slope of $\mathrm{BC}$ branch). So the inlet mixture pushes the flame back. Thus, the flame evolves into the second stable mode (i.e. B"-C" in Fig. 5c) in which the normal velocity and the local burning velocities are equal.
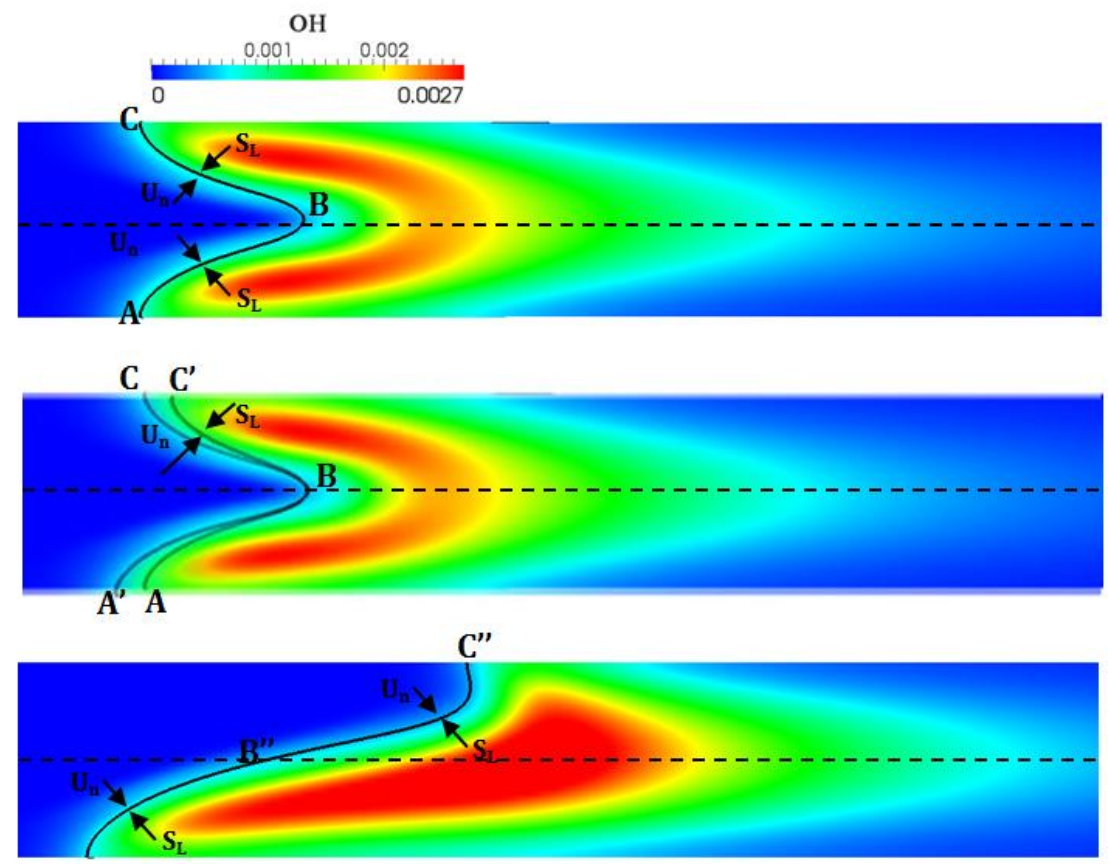

Fig. 5: Contour of $\mathrm{OH}$ representing the process of evolution a symmetric hydrogen flame into an asymmetric shape in a micro-channel with width $=1 \mathrm{~mm}$, inlet velocity $=300 \mathrm{~cm} / \mathrm{s}$ and $\varphi=0.5$.

3.2. The role of Darrieus-Landau and thermal-diffusive instabilities on the flame 
In this section, we study the interaction of thermal and mass diffusive fluxes (thermal-diffusive instability) and hydrodynamic instability (i.e. Darrieus-Landau instability) on the evolution

from a symmetric flame to an asymmetric one. As discussed above, in order to discriminate the

contribution of two instabilities on the flame behavior, we performed the computations for

different Lewis numbers, which is defined as ratio of thermal diffusive to mass diffusive. Based on the previous works (e.g., [11], [12], [30]-[32]) in order to isolate the effects of DarrieusLandau instability on the flame behavior, the assumption of unity Lewis number (Le) is made. With this assumption the effects of diffusive-thermal instability are dropped [12]. Hence, in our computation for all time steps for having a unity Lewis number, the mass diffusivity is considered to be a fixed coefficient of thermal diffusivity (i.e. $\alpha=$ D). Then, in order to examine the effect of diffusive-thermal instability, we use a non-unity Lewis number which leads to create an interaction between thermal and mass diffusive fluxes.

We first study the contribution of DL instability by performing the computations for unity $\mathrm{cm} / \mathrm{s}$ inlet velocity. Our parametric study showed that in a velocity of $300 \mathrm{~cm} / \mathrm{s}$ is an extreme case and there is a high possibility of evolving a symmetric flame into an asymmetric shape. Fig. 6 shows that as time evolves the flame remains symmetric and the maximum values of $\mathrm{OH}$ mass fraction remain on the centerline line of the channel. The computations are carried out for other 280 unstable cases and it is observed that the flame remain symmetric. Thus, it is concluded that the DL instability does not play a major role in evolving a symmetric flame into an asymmetric shape in a heated micro-channel.
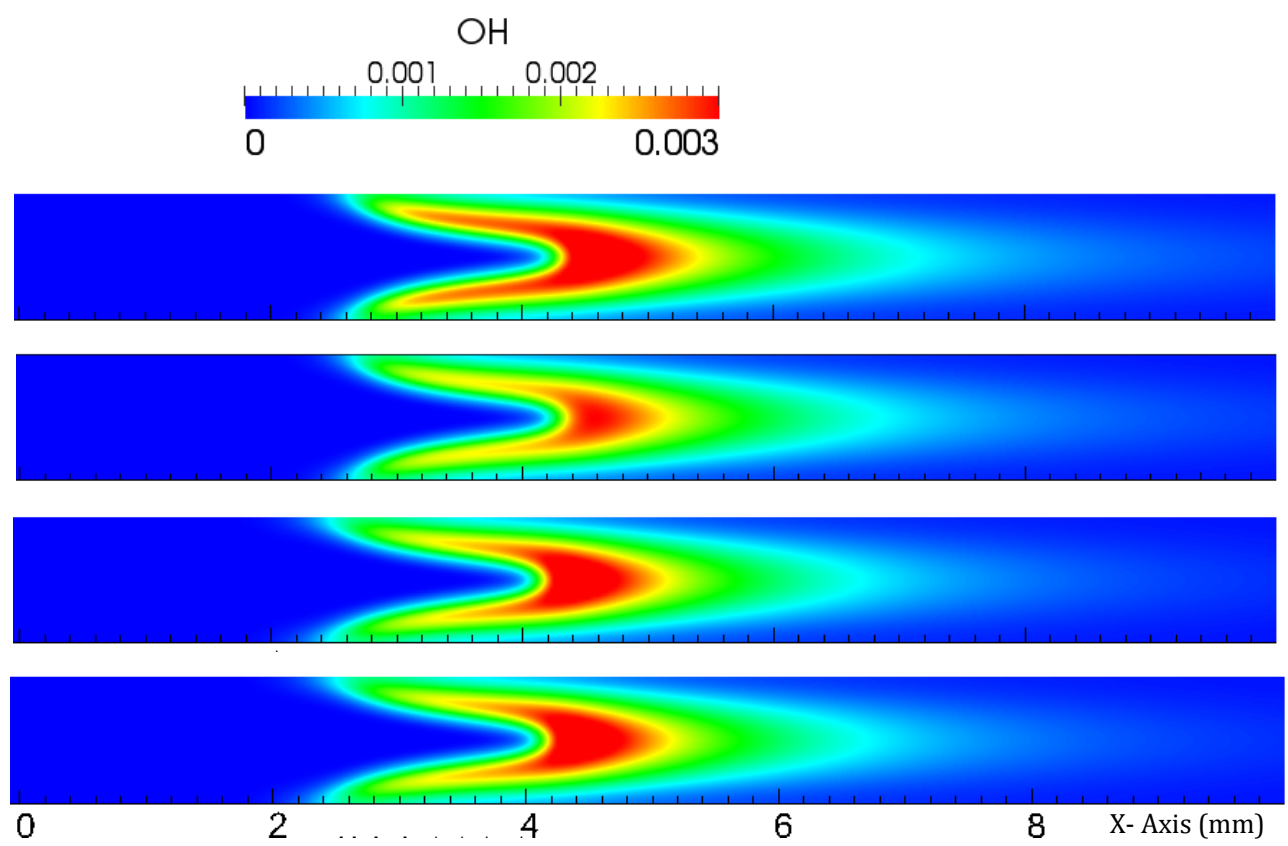

Fig. 6: Time evolution of $\mathrm{OH}$ mass fraction of a hydrogen flame in a micro-channel with Le $=1$, width $=1 \mathrm{~mm}$, inlet velocity $=300 \mathrm{~cm} / \mathrm{s}$ and $\varphi=0.5$. 
In order to study the effect of thermal-diffusive instability, the computations are

performed for nonunity Lewis numbers (this approach has been used in previous works such as

[12]). Figs. 7 and 8 show time evolution of $\mathrm{OH}$ mass fraction for two constant Lewis numbers of

Le $=1.5$ and Le $=0.35$ for a flame in a micro-channel with a width of $1 \mathrm{~mm}$ and inlet velocity of

$300 \mathrm{~cm} / \mathrm{s}$.. Lewis number of 0.35 is related to hydrogen fuel Lewis number, which has key role

in mass diffusivity. Lewis number of 1.5 is also an arbitrary number greater than one. For Lewis

number of 0.35 the thermal diffusive flux is lower than the mass diffusive flux, while for Le $=1.5$

the thermal diffusion is higher than the molecular diffusion of reactants.

$\mathrm{OH}$ mass fraction of the hydrogen flame is shown in Figs. 7 and 8 for Le $=0.35$ and Le $=$
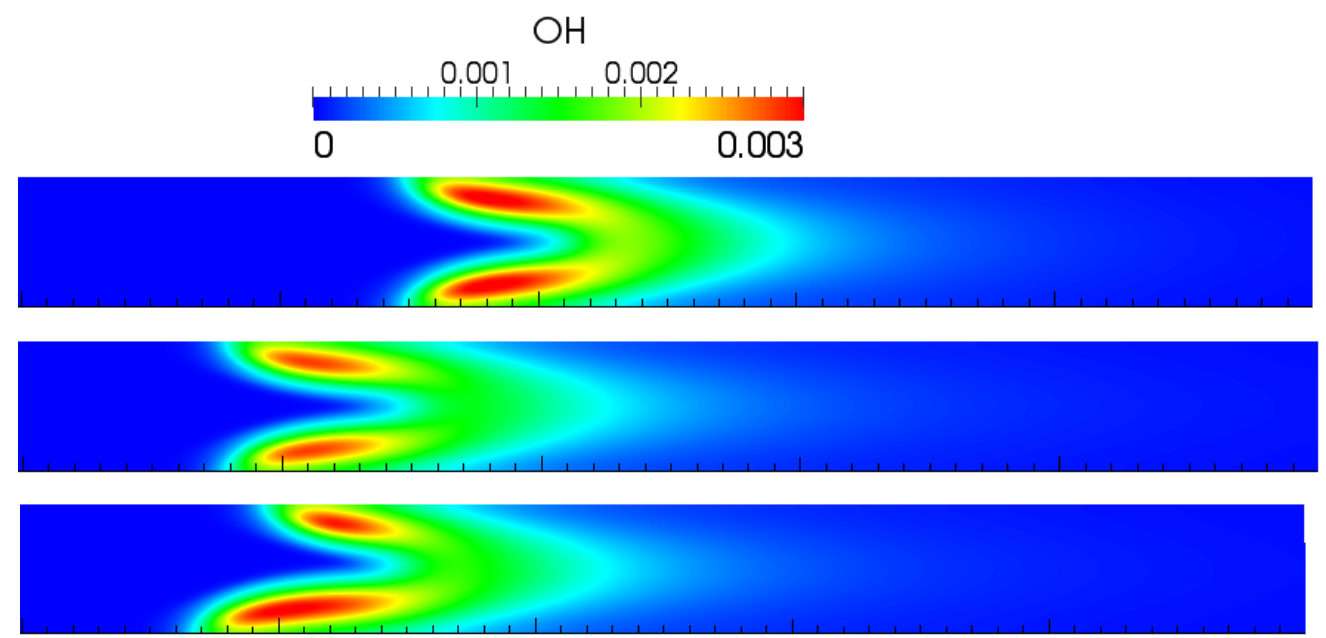

$\mathrm{t}=0.005 \mathrm{~s}$

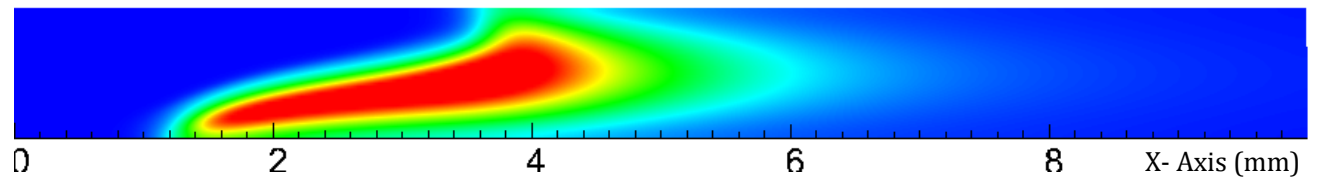

Fig. 7: Time evolution of $\mathrm{OH}$ mass fraction of a hydrogen flame in a micro-channel with Le $=0.35$, channel width $=1 \mathrm{~mm}$, inlet velocity $=300 \mathrm{~cm} / \mathrm{s}$ and $\varphi=0.5$.
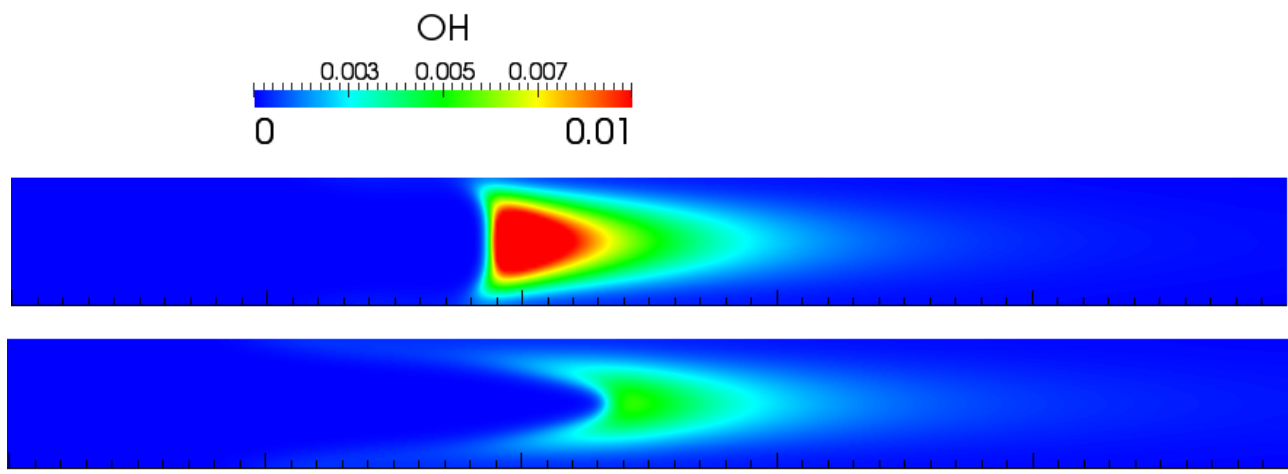

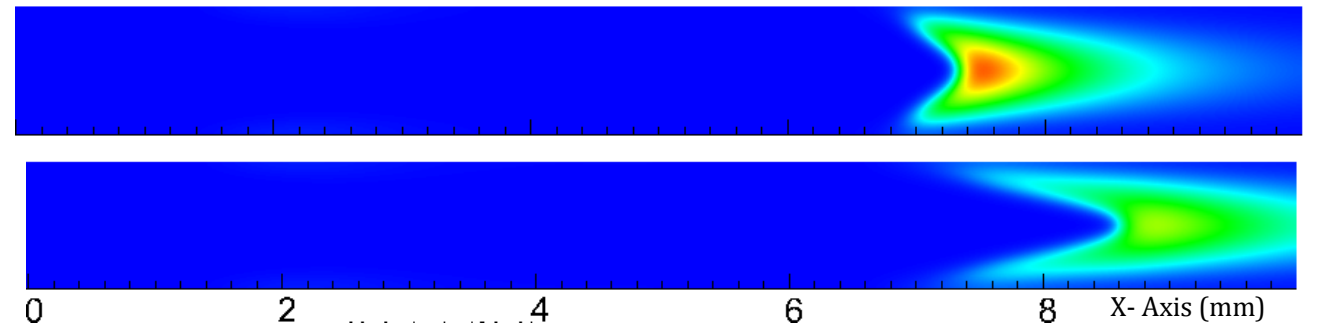

Fig. 8: Time evolution of $\mathrm{OH}$ mass fraction of a hydrogen flame in a micro-channel with Le $=1.5$, channel width $=1 \mathrm{~mm}$, inlet velocity $=300 \mathrm{~cm} / \mathrm{s}$ and $\varphi=0.5$.

To better understand the effect of nonunity Lewis number (i.e. thermal-diffusive instability) on the appearance of asymmetric flame, Fig. 9 is presented here. For Le $=0.35$, where the flame is convex toward the burnt gases, fuel diffuses in a larger area and the local flame speed decreases. In such condition, the flame is convex toward the cold mixture (Fig. 8b), the fuel diffuses faster than heat to the fresh gas (i.e. $\alpha<D$ ). So the concentration of radicals is high and the local flame speed near the walls increases. This is a typical behavior of an unstable flame where it stretches near the walls.

For Le $=1.5$, the diffusion of species to the wall decreases, so the reactions activity next to the walls also decreases. This leads to the reduction of length of flame front (length of black line) and accumulation of species and heat on the centerline of the channel. On the other hand, owing to the high diffusion of heat of combustion, the mixture entering the flame will be preheated. This causes the maximum flame temperature to be increased. The local flame speed increases due to the elevated temperature. However, since the flame is not stretched next to the walls, the stabilizing effect of the wall is not present and the flame moves toward downstream and finally exits from the channel.

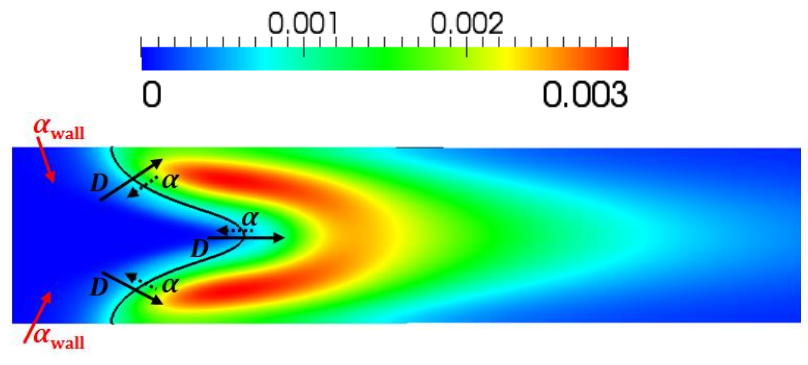

(a) Le $=0.35$

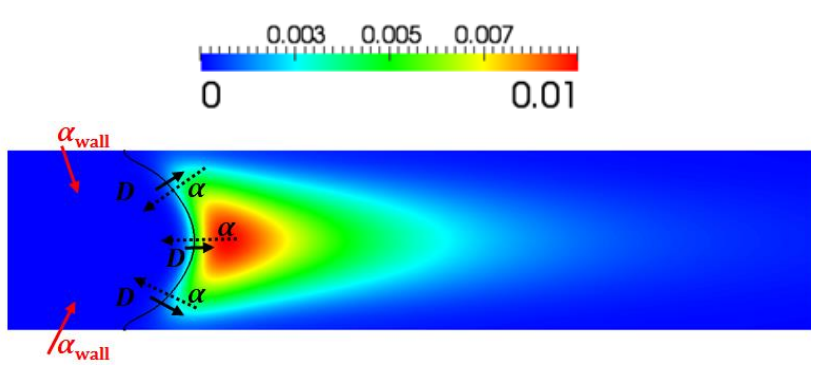

(b) Le $=1.5$

Fig. 9: Sketch of molecular and thermal diffusive flux on $\mathrm{OH}$ mass fraction contour for (a) Le $=0.35$ and

(b) Le $=01.5$. channel width $=1 \mathrm{~mm}$, inlet velocity $=300 \mathrm{~cm} / \mathrm{s}$ and $\varphi=0.5$

The results of this section clearly show that the interaction of molecular and thermal diffusions plays a major role in making the flame unstable. Using unity Lewis number assumption, it is shown that flame had symmetric shape and it can be concluded that the hydrodynamic effects are not solely responsible for the instability of the flame in micro-scales. 
In this section, the effects of the inlet velocity and the equivalence ratio $(\varphi)$ of mixture on the molecular and thermal diffusion are studied. The Lewis number as an indicator of the interaction of these diffusions is used to study these effects. Here, the diffusion coefficients are modeled based on Fick's law and hence the Lewis number is calculated during the computations using these diffusion coefficients

Lewis number is obtained on the centerline of the micro-channel for different inlet based on color line. It should be mentioned that our computations reveal that (not shown here) for inlet velocities of 30 and $50 \mathrm{~cm} / \mathrm{s}$ the flame is symmetric, while for 80 and $200 \mathrm{~cm} / \mathrm{s}$ velocities the flame exhibits an asymmetric behavior.

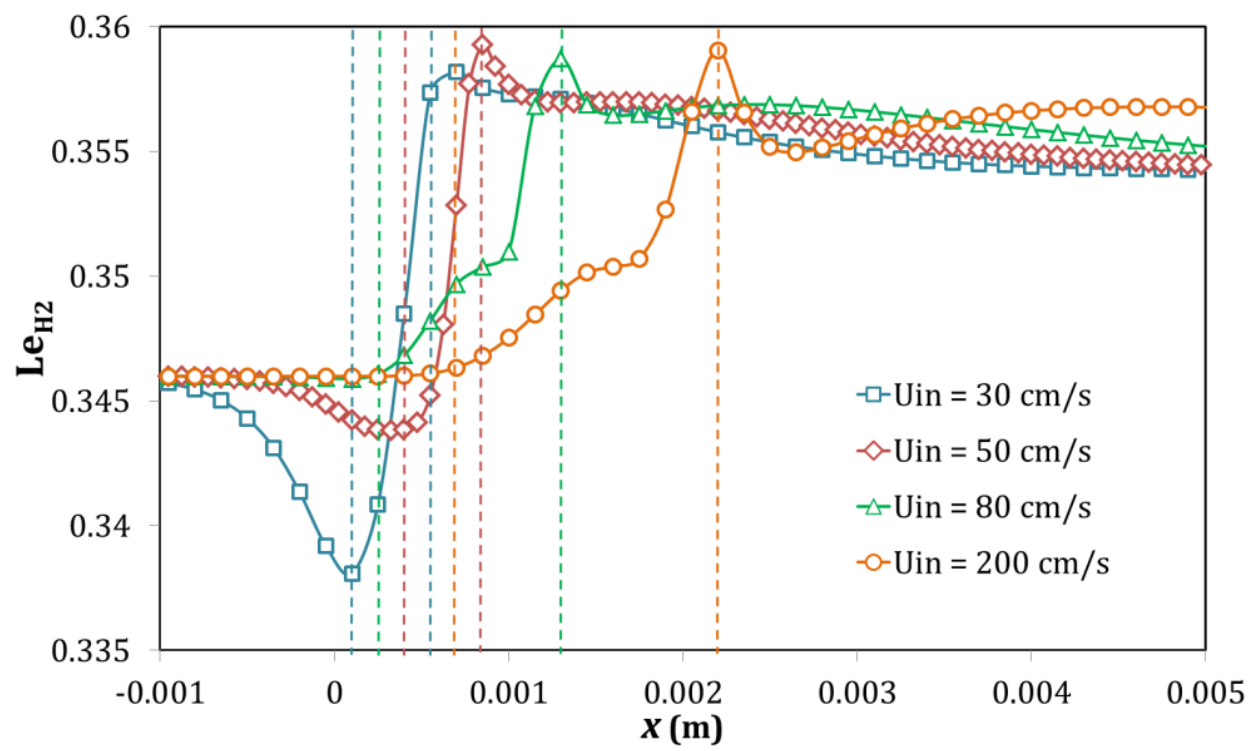

Fig. 10: Variation of Lewis number of hydrogen on centerline of the channel for different inlet velocities with channel width $=1 \mathrm{~mm}$ and $\varphi=0.5$.

Fig. 10 shows that for low inlet velocities of $30 \mathrm{~cm} / \mathrm{s}$ and $50 \mathrm{~cm} / \mathrm{s}$ (in which the flame has a symmetric shape) Lewis number behind the flame front (i.e. vertical dashed line)decreases along the centerline. We observed this behavior for different channel widths, inlet velocities and equivalence ratios. While for higher inlet velocities in Fig. 10 where the flame has an asymmetric shape, the Lewis number remains almost constant behind the flame front.

In Fig. 11, the behavior of Lewis number is depicted for different equivalence ratios when the flame has a symmetric shape. For attaining symmetric flames, different inlet velocities were 
alters by the increase equivalence ratio and hence in order to have a symmetric flame we need to increase the inlet velocity accordingly.

To illustrate qualitatively this behavior, the contour of temperature is shown in Fig. 12. As mentioned above, unlike $30 \mathrm{~cm} / \mathrm{s}$, the flame in $80 \mathrm{~cm} / \mathrm{s}$ inlet velocity is unstable and finally evolves into an asymmetric flame. In this figure the black lines represent the flame front. In addition, $\alpha, D, \alpha_{\text {wall }}$ and $h_{\text {conv }}$ are thermal diffusive flux from flame to the flow, mass diffusive flux from the cold flow to the flame, heat diffusion from the hot walls to the flow and convective heat transfer from the flame to the cold flow, respectively.

By increasing the inlet velocity, $\mathrm{h}_{\text {conv }}$ increases. This leads to the reduction of flow temperature on the centerline of the channel. Further, due to the high temperature of the walls the flame stretches close to the walls. This leads to the increase of flame surface. By increasing the inlet velocity, the flame moves toward downstream. The flame is more convex toward the products in $80 \mathrm{~cm} / \mathrm{s}$ than $30 \mathrm{~cm} / \mathrm{s}$ inlet velocity and the flame surface increases. This leads to the inclination of the normal flux of mass and thermal diffusions. The mass diffusion vectors point toward the walls and the thermal diffusion vectors point toward the centerline. As seen 350 schematically in this figure, for symmetric case, the heat diffusion fluxes augment to each other and increase the heat concentration on the center line. While molecular diffusion fluxes cancel 352 out each other. So the Lewis number behind the flame will increase due to the increasing of $\alpha$ and decreasing of $\mathrm{D}$.

For inlet velocity of $80 \mathrm{~cm} / \mathrm{s}$, the mixture entering the flame near the walls has a higher temperature since it is preheated more by the walls (compare Fig. $12 \mathrm{~b}$ with compare with Fig. 12.). So the flame is stretched near the walls. On the other hand, due to the increased velocity, 


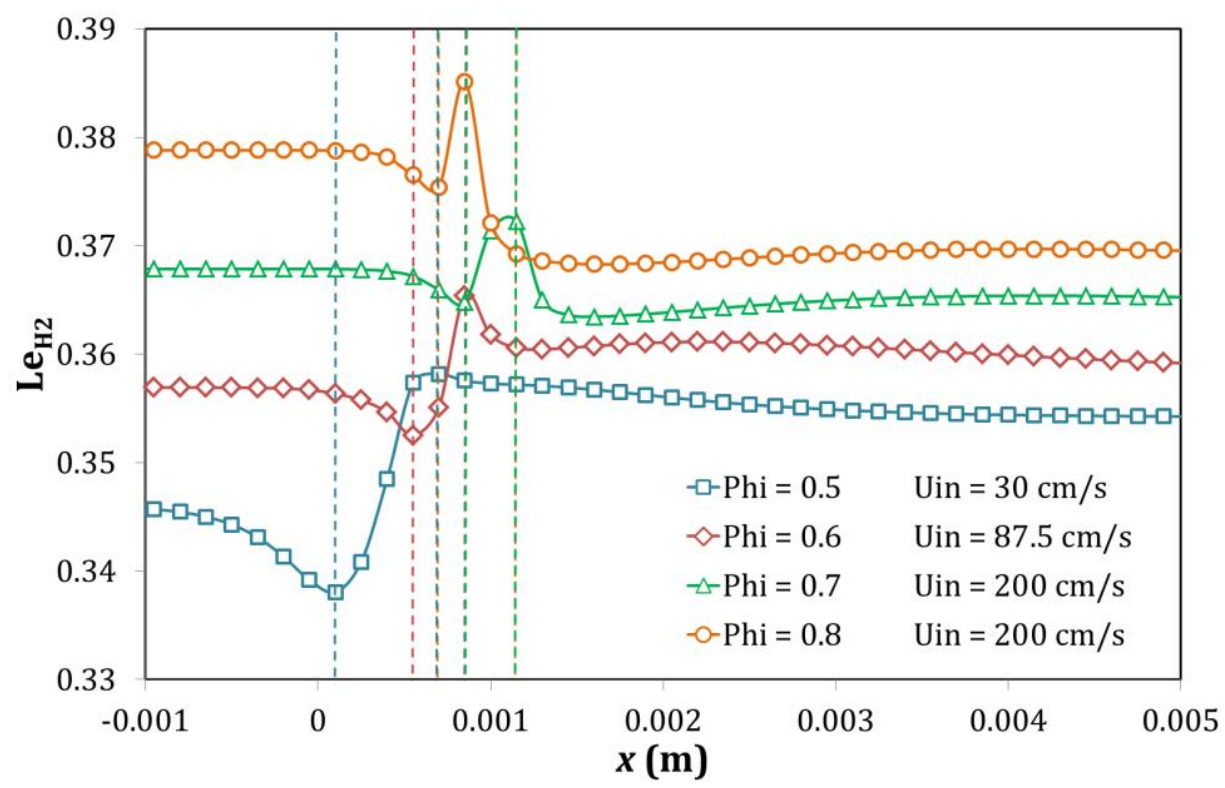

Fig. 11: Variation of Lewis number of hydrogen on centerline of channel for different inlet velocities and equivalence ratio with channel width $=1 \mathrm{~mm}$.

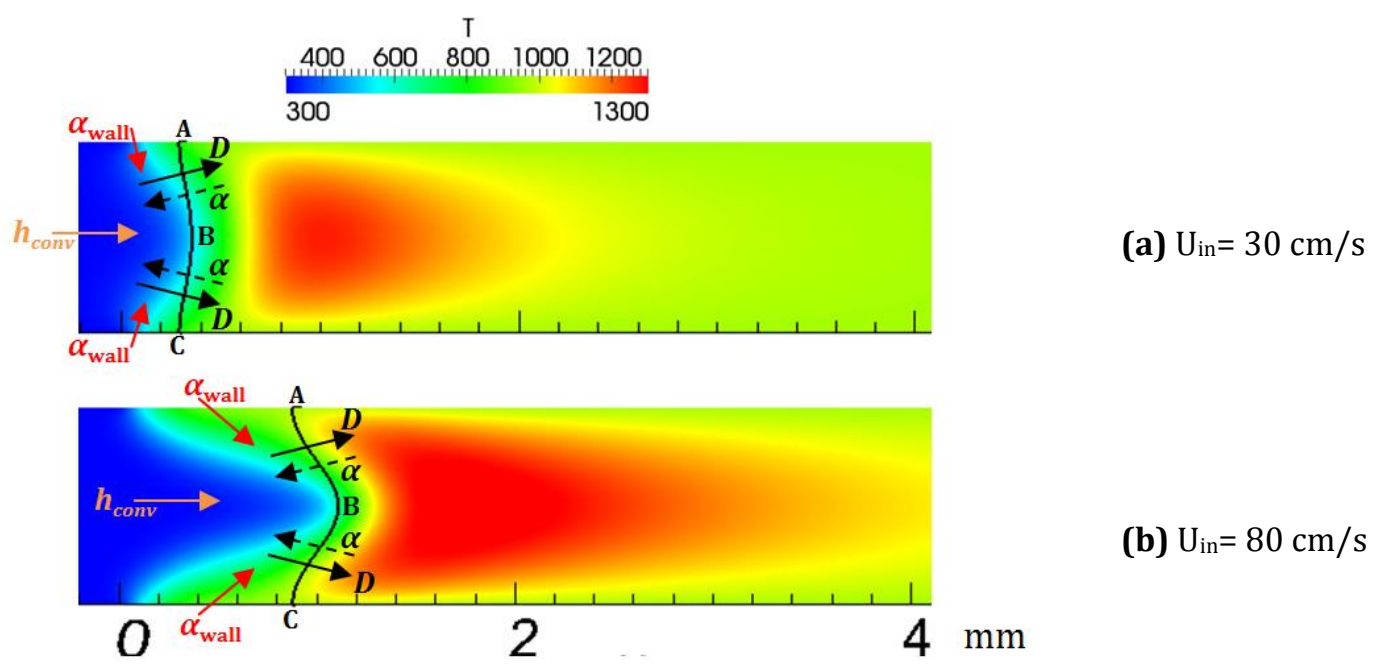

Fig. 12: Qualitative illustration of asymmetric behavior of flame. Channel width $=1 \mathrm{~mm}$ and $\varphi=0.5$. (a)

$$
\mathrm{U}_{\mathrm{in}}=30 \mathrm{~cm} / \mathrm{s} \text { and }(\mathrm{b}) \mathrm{U}_{\mathrm{in}}=80 \mathrm{~cm} / \mathrm{s} \text {. }
$$

\subsection{A criteria for asymmetric behavior of flame}

As mentioned above, the length of flame front (length of A-B-C line in Fig. 12) is an important parameter in the flame behavior. To study the role of this parameter, a new dimensionless parameter, $\mathrm{h}_{\mathrm{fs}}$, is defined as the ratio of length of flame front to channel width. In Fig. 13, this parameter is illustrated under different inlet conditions.

In this figure, the gray lines represent the symmetric flames and the black lines represent the asymmetric flames. For the flames that finally evolve into the asymmetric shape, the length 
of flame front is evaluated ${ }^{1}$ and shown both before and after the transition to an asymmetric

shape. For equivalence ratios below unity, the length of asymmetric flames is more than the

symmetric ones. However, in equivalence ratios above unity this trend is reversed. So the length

of flame front for asymmetric flames becomes less than the symmetric ones. This can be due to

It is seen that for $\mathrm{h}_{\mathrm{fs}}$ in the interval between 1.1 and 1.15 the instability is occurred and the flame becomes asymmetric in shape. This range of $h_{f s}$ has been also observed for various channel heights.

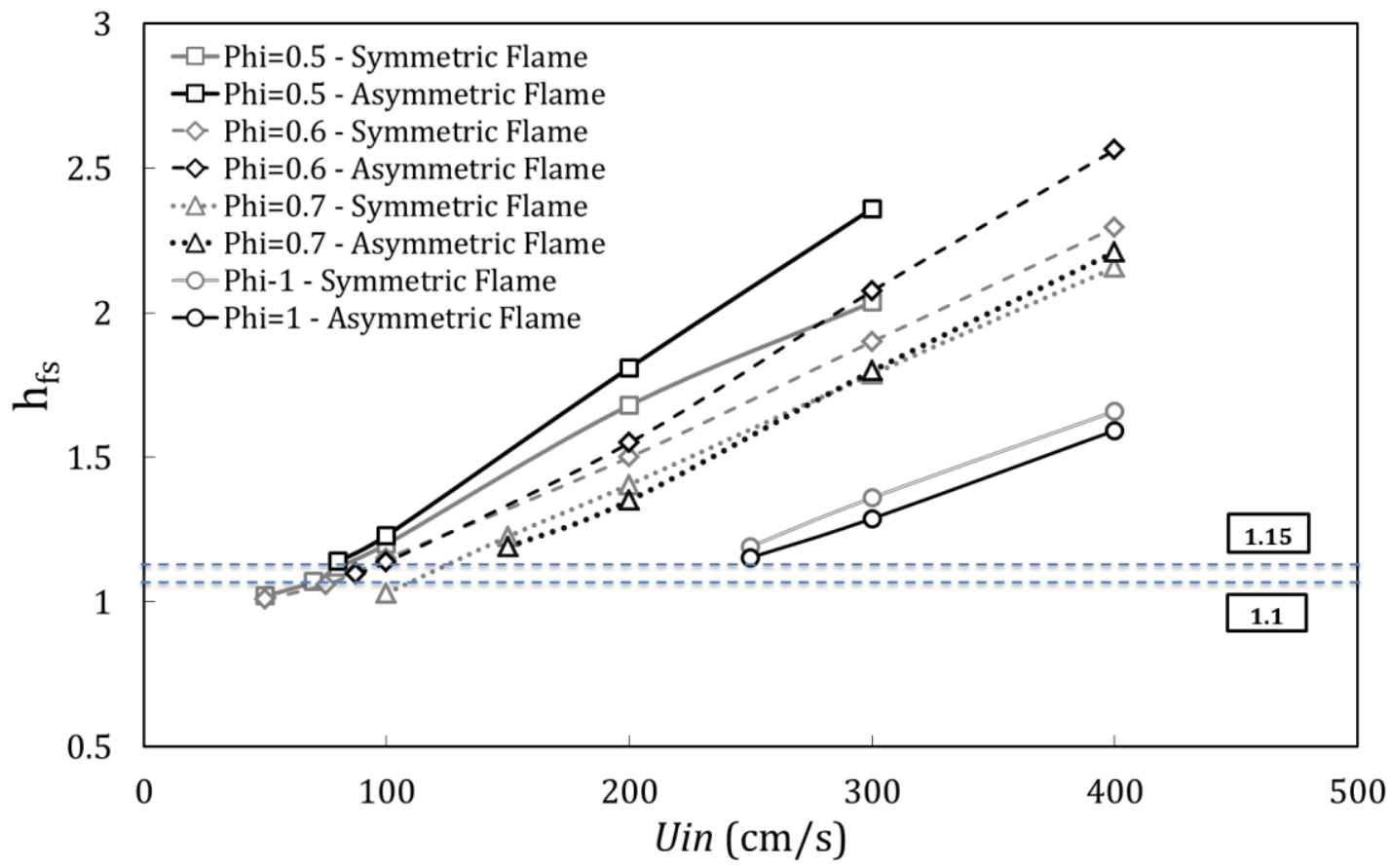

Fig. 13: Variation of $\mathrm{h}_{\mathrm{fs}}$ (length of flame front to channel width ratio) in different inlet velocities and equivalence ratio for $1 \mathrm{~mm}$ channel width.

\section{Conclusions}

In the present work the asymmetric behavior of flame in micro-scales is studied numerically. The combustion of hydrogen/air mixture in a micro-channel is simulated using a reactive solver developed based on low-Mach number formulation incorporating detailed chemical kinetics and multi species transport model. It is found that by increasing the inlet velocity for a channel of fixed width, the flame stretches near the wall. At this moment, the flame is unstable and ready to become asymmetric due to existing perturbations. The Lewis number is used to study the effects of different types of instabilities on the flame front. First in order to analysis the role of different instabilities we artificially set the Lewis number in the computations to be a fixed number. For unity Lewis number, the flame is stable and symmetric,

1 The length is be obtained in post processing step utilizing image processing 
and does not evolve into an asymmetric shape. This clarifies that Darrieus-Landau has no

profound role in appearance of asymmetric flames in heated micro-channels. While, for Lewis

number less than unity, evolution of a symmetric flame into an asymmetric shape is observed.

This clearly shows that the diffusive-thermal instability plays a major role in the formation of asymmetric flames in micro-channels with preheated walls.

Second, to study the role of thermal and mass diffusions, these parameters were exists a reduction of the Lewis number behind the flame front. This is due to the alternation in

\section{Acknowledgment}

The authors would like to thank Professor Paul D. Ronney of the University of Southern

\section{References}

[1] J. Wan, A. Fan, K. Maruta, H. Yao, and W. Liu, Experimental and numerical investigation on

[2] J. Wan, W. Yang, A. Fan, Y. Liu, H. Yao, W. Liu, Y. Du, and D. Zhao, "A numerical investigation on

[3] Y. Yan, W. Tang, L. Zhang, W. Pan, Z. Yang, Y. Chen, and J. Lin, Numerical simulation of the effect of 409 hydrogen addition fraction on catalytic micro-combustion characteristics of methane-air, Int. J. Hydrogen Energy, 39 (2014), pp. 1864-1873.

[4] G. Pizza, C. E. Frouzakis, J. Mantzaras, A. G. Tomboulides, and K. Boulouchos, Dynamics of premixed hydrogen/air flames in microchannels, Combust. Flame, 152 (2008), pp. 433-450.

[5] U. R. S. Dogwiler, J. Mantzaras, P. Benz, B. Kaeppeli, and R. Bombach, Homogeneous ignition of 
[7] V. Kurdyumov, E. Fernández-Tarrazo, J.-M. Truffaut, J. Quinard, A. Wangher, and G. Searby,

[8] F. A. Williams, Combustion Theory. The Benjamin/Cummings Publish ing Company, Inc., 1985.

[9] C. K. Law and C. K. Law, Combustion Physics, 1st ed. Cambridge university press, 2006.

[10] V. N. Kurdyumov, G. Pizza, C. E. Frouzakis, and J. Mantzaras, Dynamics of premixed flames in a

[11] G. I. Sivashinsky, Instabilities, Pattern Formation, and Turbulence in Flames, Annu. Rev. Fluid

[12] C. Altantzis, C. E. Frouzakis, a. G. Tomboulides, M. Matalon, and K. Boulouchos, Hydrodynamic and

[13] A. Petchenko and V. Bychkov, Axisymmetric versus non-axisymmetric flames in cylindrical tubes, Combust. Flame, 136 (2004), pp. 429-439.

[14] C.-H. Tsai, The Asymmetric Behavior of Steady Laminar Flame Propagation in Ducts, Combust.

[15] M. Liberman, M. Ivanov, O. Peil, D. Valiev, and L.-E. Eriksson, Numerical studies of curved 435 stationary flames in wide tubes, Combust. Theory Model., 7 (2003), pp. 653-676.

[16] V. V. Bychkov and M. A. Liberman, Dynamics and stability of premixed flames, Phys. Rep., 325

[17] Y. J. I. Kaisare N. S., Stefanidis GD., Vlachos DG. In: Hessel V, Schouten J.C., Renken A, Transport catalysts. Wiley, 2009.

[18] N. S. Kaisare and D. G. Vlachos, A review on microcombustion: Fundamentals, devices and applications, Prog. Energy Combust. Sci., 38(2012), pp. 321-359.

[19] C. H. H. Kuo and P. D. D. Ronney, Numerical modeling of non-adiabatic heat-recirculating combustors, Proc. Combust. Inst., 31(2007), pp. 3277-3284.

[20] G. Pizza, C. E. Frouzakis, J. Mantzaras, A. G. Tomboulides, K. Boulouchos, and A. T. G., Dynamics of 446 premixed hydrogen/air flames in mesoscale channels, Combust. Flame, 155 (2008), pp. 2-20.

[21] G. Pizza, J. Mantzaras, C. E. Frouzakis, A. G. Tomboulides, and K. Boulouchos, Suppression of 
[23] S. R. Turns, An Introduction to Combustion : Concepts and Applications, Second Edi. Mc Graw Hill,

[24] E. Miyata, N. Fukushima, Y. Naka, M. Shimura, M. Tanahashi, and T. Miyauchi, Direct numerical

[25] S. Kikui, T. Kamada, H. Nakamura, T. Tezuka, S. Hasegawa, and K. Maruta, Characteristics of n-

[26] T. Kamada, H. Nakamura, T. Tezuka, S. Hasegawa, and K. Maruta, Study on combustion and

[27] J. Li, Y. Wang, J. Shi, and X. Liu, Dynamic behaviors of premixed hydrogen - air flames in a planar 464 micro-combustor filled with porous medium, Fuel, 145 (2015), pp. 70-78.

[28] R. A. Yetter, F. L. Dryer, and H. Rabitz, "A comprehensive reaction mechanism for carbon 466 Monoxide/Hydrogen/Oxygen kinetics, Combust. Sci. Technol., 79 (1991), pp. 97-128.

[29] A. Alipoor and K. Mazaheri, Studying the repetitive extinction-ignition dynamics for lean 468 premixed hydrogen-air combustion in a heated microchannel, Energy, 73 (2014), pp. 367-379.

[31] N. Bouvet, F. Halter, C. Chauveau, and Y. Yoon, On the effective Lewis number formulations for lean hydrogen/hydrocarbon/air mixtures, Int. J. Hydrogen Energy, 38 (2013), pp. 5949-5960. 